\title{
Proteomic Analysis of Plasma Membrane Proteins of Antler Stem Cells Using Label-Free LC-MS/MS
}

\author{
Datao Wang ${ }^{1}$, Hengxing Ba ${ }^{1}\left(\mathbb{D}\right.$, Chenguang $\mathrm{Li}^{1,2}$, Quanmin Zhao ${ }^{2}$ and Chunyi $\mathrm{Li}^{1,3, *}$ \\ 1 Institute of Special Wild Economic Animals and Plants, Chinese Academy of Agricultural Sciences, \\ Changchun 130112, China; wangdatao@caas.cn (D.W.); bahengxing@caas.cn (H.B.); \\ lichenguang0916@gmail.com (C.L.) \\ 2 College of Life Sciences, Jilin Agricultural University, Changchun 130118, China; \\ zhaoquanmin6688@gmail.com \\ 3 Department of Biology, Changchun Sci-Tech University, Changchun 130600, China \\ * Correspondence: lichunyi1959@163.com; Tel.: +86-431-81919500
}

Received: 14 September 2018; Accepted: 3 November 2018; Published: 5 November 2018

\begin{abstract}
Deer antlers are unusual mammalian organs that can fully regenerate after annual shedding. Stem cells resident in the pedicle periosteum (PPCs) provide the main cell source for antler regeneration. Central to various cellular processes are plasma membrane proteins, but the expression of these proteins has not been well documented in antler regeneration. In the present study, plasma membrane proteins of PPCs and facial periosteal cells (FPCs) were analyzed using label-free liquid chromatography-mass spetrometry (LC-MS/MS). A total of 1739 proteins were identified. Of these proteins, 53 were found solely in the PPCs, 100 solely in the FPCs, and 1576 co-existed in both PPCs and FPCs; and 39 were significantly up-regulated in PPCs and 49 up-regulated in FPCs. In total, 226 gene ontology (GO) terms were significantly enriched from the differentially expressed proteins (DEPs). Five clusters of biological processes from these GO terms comprised responses to external stimuli, signal transduction, membrane transport, regulation of tissue regeneration, and protein modification processes. Further studies are required to demonstrate the relevancy of these DEPs in antler stem cell biology and antler regeneration.
\end{abstract}

Keywords: deer antler; antler stem cell; membrane protein; label-free LC-MS/MS; regeneration

\section{Introduction}

The ultimate goal of modern regenerative biology and medicine is to achieve tissue/organ regeneration [1]. Classic models for regeneration studies, such as planaria, zebrafish and salamander, are lower-level animals. Thus, it is not known whether the mechanisms underpinning these regeneration models can be applied to mammals, including human beings. Deer antlers are unusual mammalian organs that can fully regenerate after annual shedding [2,3] and a unique case of stem cell-based mammalian organ regeneration. Morphological and histological studies showed that the distal pedicle periosteum (PP) provides the main cell source for antler regeneration [4-6]. PP deletion and membrane insertion experiments demonstrated that $\mathrm{PP}$ is the key tissue type that initiates antler regeneration [7]. PP cells (PPC) possess stem cell attributes, such as the markers CD9, CD105, Stro-1, Oct4, Nanog, and SOX2. Rolf, et al. [8] isolated Stro-1+ cells from the PP and antler tip tissues and defined these cells as a type of mesenchymal stem cell. Further characterization of antler stem cells (ASCs) is a prerequisite for advancing our knowledge of antler regeneration.

One key area lacking in understanding of ASCs is our knowledge of proteins associated with the cell membrane in these cells. Membrane proteins represent one-third of the total proteins encoded in the human genome [9]. Due to their interfacial position in cells, plasma membrane proteins play 
central roles in various cellular processes including signal transduction, cell adhesion, and transport of molecules [10]. While the proteome of ASCs has been studied previously [11-13], the majority of differentially expressed proteins (DEPs) and special markers identified were natively soluble proteins. Membrane proteins, characterized by heterogeneity, hydrophobicity, and low abundance, were discarded in these studies since no special enrichment was adopted.

In this study, the plasma membrane proteins of PPCs and deer facial periosteal cells (FPCs) were isolated from their respective tissues and enriched using gradient centrifugation and different solvents. The FPCs were specifically selected to serve as a control as these cells locate in the vicinity of the PPCs and have the most attributes of PPCs, but do not have ability to regenerate antlers [14]. Label-free liquid chromatography-mass spectrometry (LC-MS) was used in this study to detect and analyze the composition of the membrane proteins and the differences between them. Following gene ontology (GO) analysis of DEPs, it was shown that we had successfully enriched plasma membrane proteins. Stem cell surface markers such as CD9, CD29, CD44, CD73, CD90, CD105, and CD166 were detected in the PPCs. GO analysis provided a general profiling for DEPs, and Kyoto Encyclopedia of Genes and Genomes (KEGG) pathway analysis identified some receptors regulated biological pathways in the PPCs. Overall, this study contributes to our understanding of the molecular basis of the stem cells driving antler regeneration.

\section{Results}

\subsection{Summary of Label-Free Liquid Chromatography-Mass Spetrometry (LC-MS/MS) Results}

In total, 1739 proteins were identified. Of these proteins, 1586 co-existed in both the PPCs and FPCs; 53 solely in the PPCs and 100 in the FPCs (Supplementary S1). Of the 1586 proteins, 39 were significantly up-regulated in PPCs $(p<0.05)$ and 49 significantly up-regulated $(p<0.05)$ in the FPCs (Figure 1). Therefore, we obtained $241(53+100+39+49)$ DEPs in total. All identified proteins were annotated online (available online: http:/ / david.abcc.ncifcrf.gov/, accessed on 9 February 2018), and GO terms containing the key words "plasma membrane" were deemed to be plasma membrane proteins. In the PPCs, plasma membrane proteins accounted for $40.9 \%$ (671 out of 1639), and in the FPCs for $40.6 \%$ (685 out of 1686). We evaluated the proteomics of PPCs reported by Dong et al. [12] in the same way, and found that $16.3 \%$ (407 out of 2500 ) were plasma membrane protein.
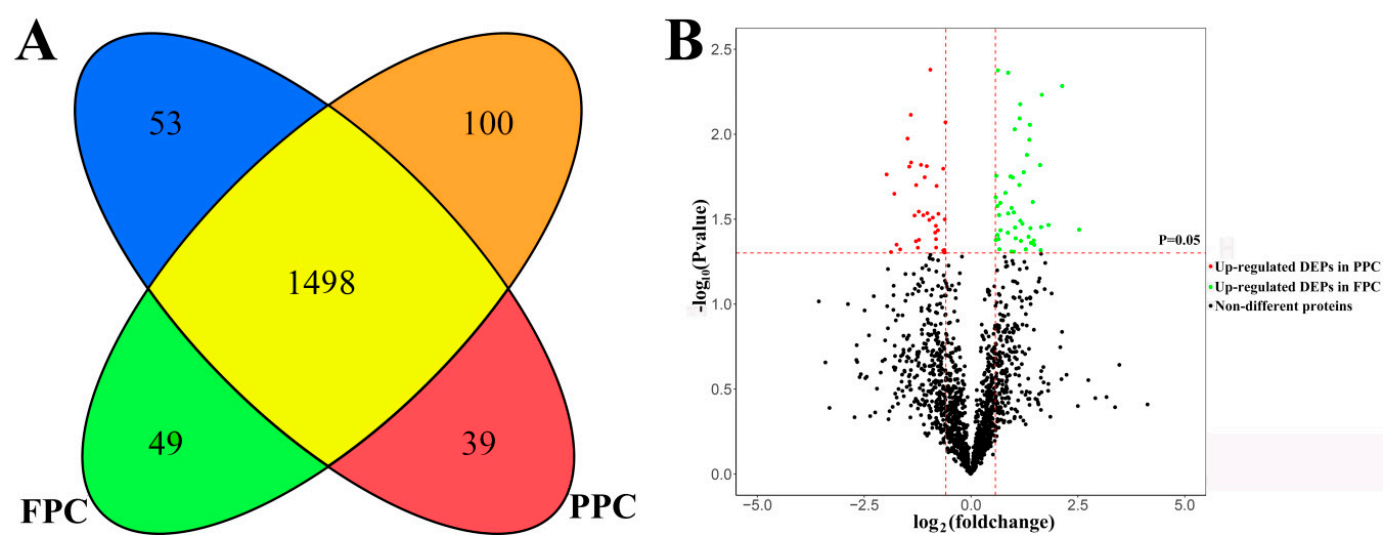

Figure 1. Summary of liquid chromatography-mass spectrometry (LC-MS/MS) results. (A) A cartoon showing the intersection of differentially expressed proteins (DEPs) between the pedicle periosteum cells (PPCs) and facial periosteal cells (FPCs), 53 proteins were found solely in the PPCs (O) and 100 solely in the FPCs (O). 1498 co-existed in both the PPCs and FPCs without significant difference in expression level ( ), 39 were significantly up-regulated in the PPCs $(O)$ and 49 up-regulated in the FPCs (O). (B) A volcano plot displays fold changes and $p$-values of starting MaxQuant data. Fold change $>1.5$ and $p<0.05$ were defined as significant difference. 


\subsection{Functional Classification of Differentially Expressed Proteins (DEPS)}

Gene ontology (GO) annotation and enrichment of DEPs were carried out using online software (available online: http:/ / david.abcc.ncifcrf.gov/, accessed on 9 February 2018). A total of 226 GO terms were significantly enriched $(p<0.05)$. Of these, 124 were involved in "biological processes", 17 in "molecular function" and 85 in "cellular component" (Supplementary S2). The top 10 GO terms from each category were selected (Figure 2) and showed that the predominant terms in "cell component" were membrane or membrane associated proteins; in "biological processes" were localization and transport proteins; and in "molecular function" were binding proteins.
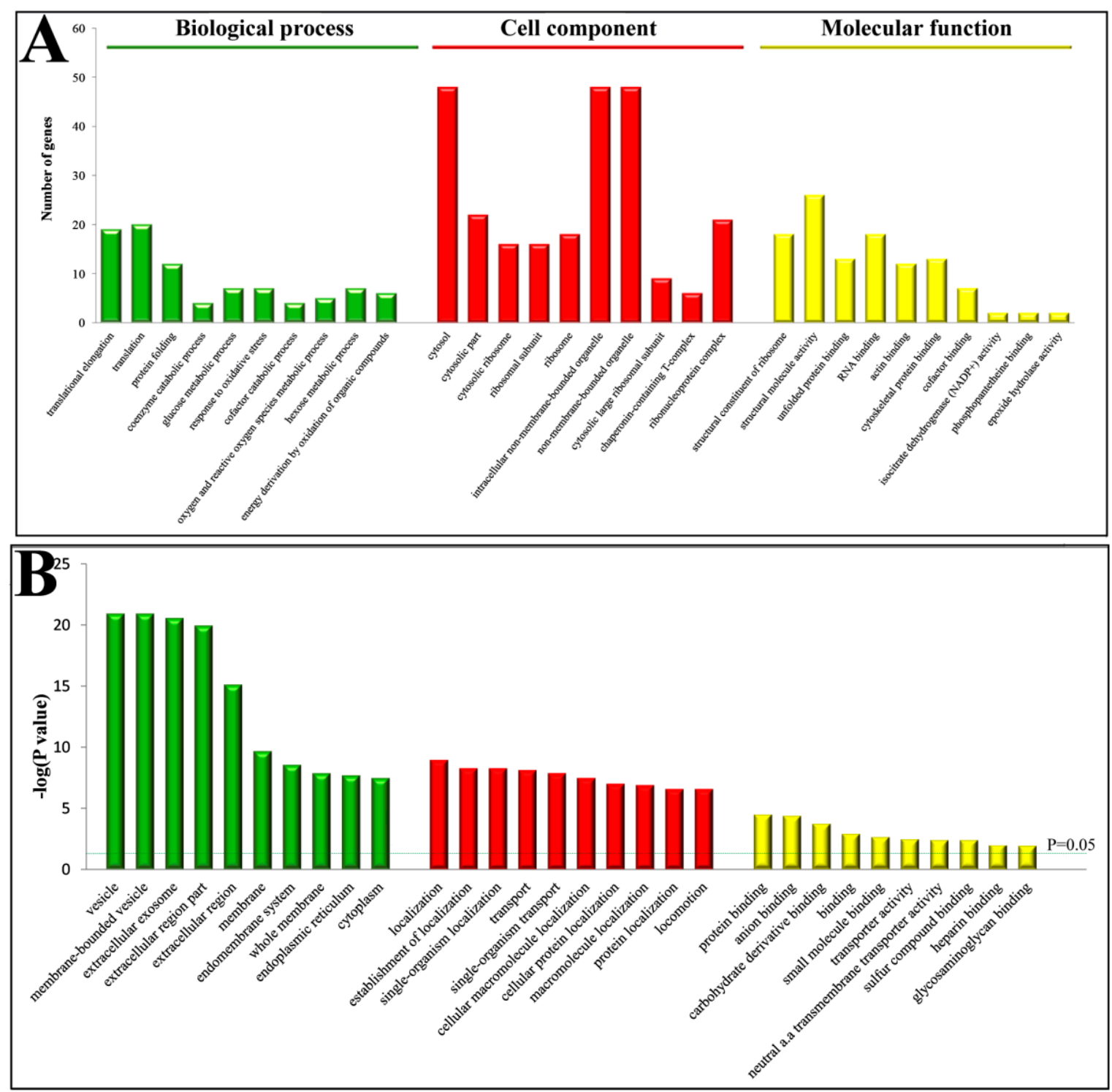

Figure 2. Gene ontology (GO) enrichment analysis of DEPs in the PPCs vs. FPCs. (A) Top 10 of each group were involved in "biological processes", "molecular function" and "cellular component". (B) $p$ values of GO terms were indicated.

The enriched GO terms were further grouped using the EnrichmentMap plusin tool in Cytoscape 3.1.1 [15,16] to generate a weighted similar network (Figure 3). Five representative clusters were generated: (1) in response to external stimulus (8 terms); (2) signal transduction (11 terms); (3) membranous transport (23 terms); (4) regulation of tissue regeneration (24 terms); and (5) protein modification (16 terms). 


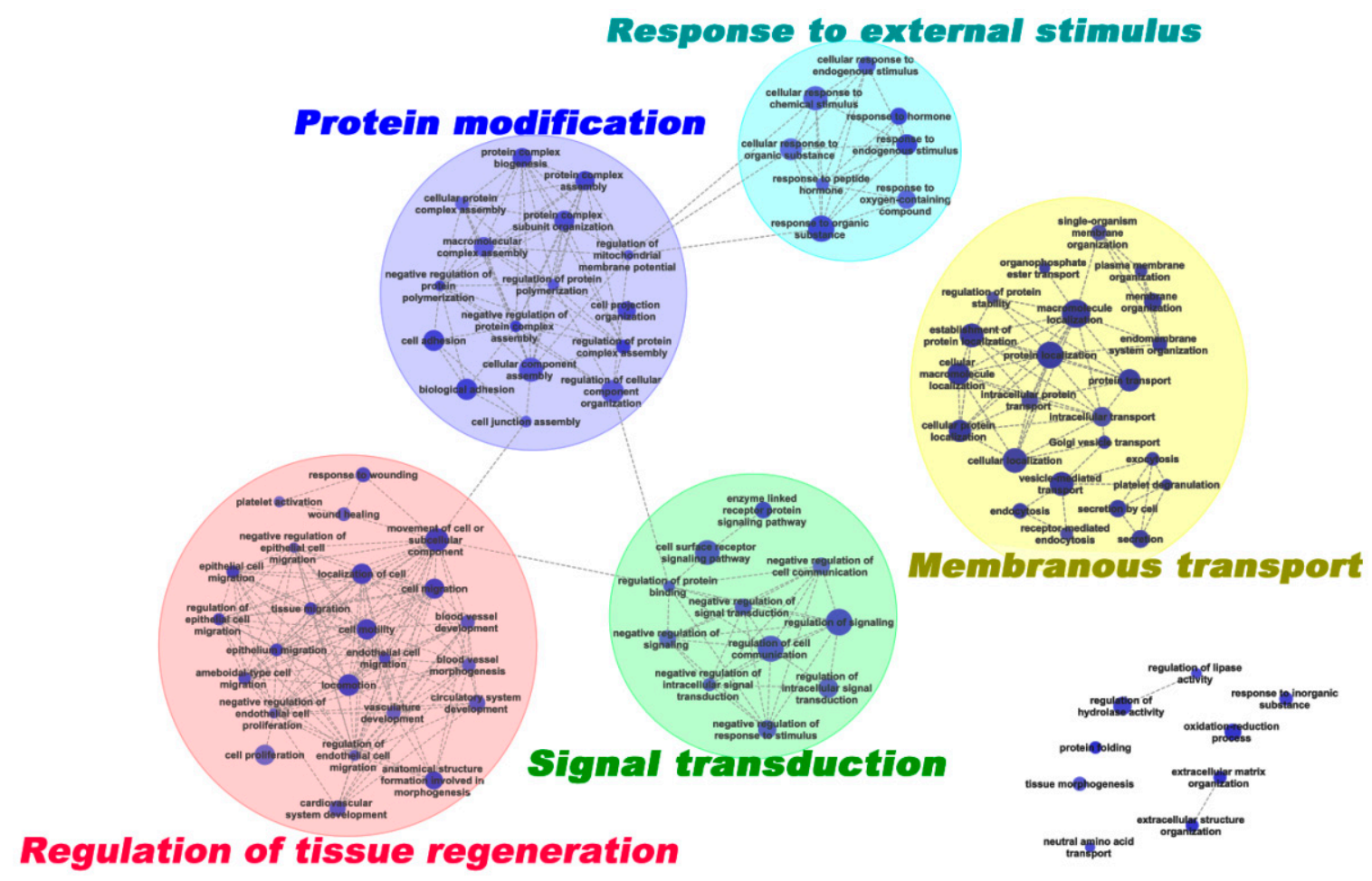

Figure 3. Network of enriched GO terms derived from DEPs. The enriched GO terms are organized as a weighted similar network, with nodes representing enriched GO terms (adj. $p<0.05$ ) and edges representing the overlap score (coeffcient cutoff of 0.5), calculated from the number of proteins shared by two GO terms.

\subsection{Interactive Network DEPs}

The interactive networks of DEPs were analyzed online (available online: https:/ / string-db.org. version 10.0). One hundred and fifty nine of the 241 DEPs were shown to be involved in the interactive network (28 up-regulated and 38 down-regulated, PPC vs. FPC; 35 solely in the PPCs and 58 in the FPCs), and fold change of proteins was indicated in gradient color (Figure 4). Critical node-proteins in the interactive network were identified following the method mentioned by Boginski and Commander [17]; SPARC (secreted acidic cysteine rich glycoprotein), SRC (Proto-oncogene tyrosine-protein kinase Src), ITGA3 (Integrin alpha-3), TIMP2 (Metalloproteinase inhibitor 2) and TF (Serotransferrin), were identified as critical node-proteins of the network. 

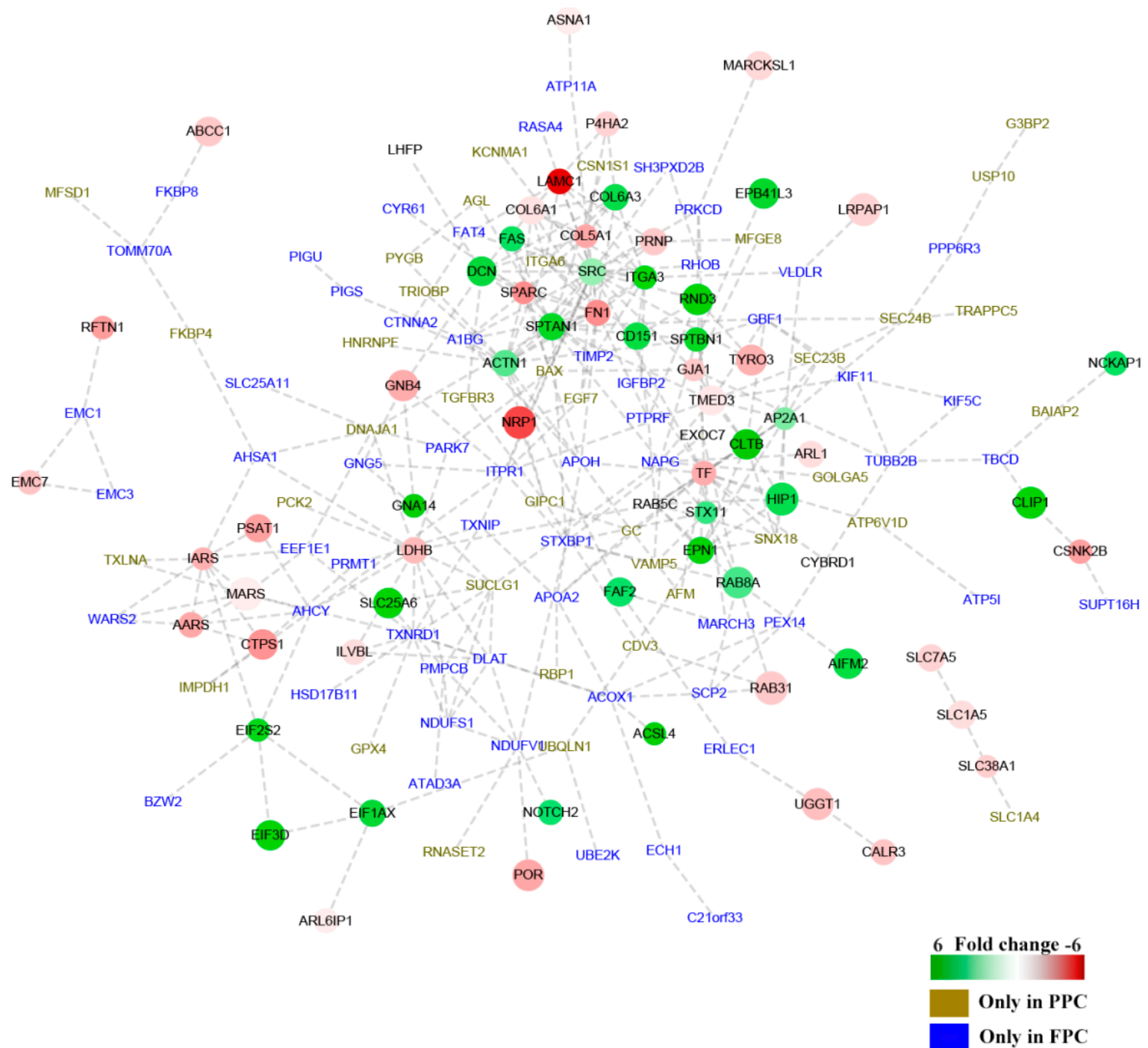

Figure 4. Interaction network of DEPs in the PPCs vs. FPCs. The panorama network consists of 159 DEPs, including 28 up-regulated proteins, 38 down-regulated proteins in the PPCs, 35 solely detected

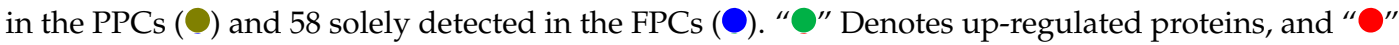
denotes down-regulated proteins in the PPCs. Bar color was considered as a logarithmic scale from -6.00 to 6.00 .

\subsection{Enriched Signaling Pathways}

Six pathways of the KEGG were significantly enriched $(p<0.05)$ from the DEPs (Table 1$)$. The extracellular matrix (ECM)-receptor interaction signal pathway significantly dominated and seven related proteins were differentially expressed (Figure 5). For some signal pathways, such as PI3K/AKT and VEGF, although not significantly enriched, key node proteins in the pathways were differentially expressed (Figure S1). Transcriptome data published by our laboratory [12] were used to map whole signal pathways. 
Table 1. Kyoto Encyclopedia of Genes and Genomes (KEGG) pathways enriched in the PPCs vs. FPCs.

\begin{tabular}{|c|c|c|c|}
\hline Pathway Description & $\begin{array}{l}\text { Protein } \\
\text { Count }\end{array}$ & $p$ Value & $\begin{array}{c}\text { Matching Proteins (Labels), } \\
\text { “个” Up-Regulation, “ } \downarrow \text { ” Down-Regulation }\end{array}$ \\
\hline $\begin{array}{c}\text { Extracellular matrix } \\
\text { (ECM)-receptor interaction }\end{array}$ & 7 & 0.00882 & 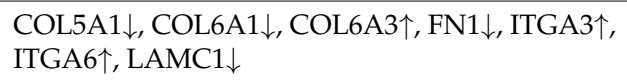 \\
\hline Adherens junction & 6 & 0.0111 & $\begin{array}{l}\text { ACTN1 } 1, \text { BAIAP2 } \uparrow, \text { CTNNA2 } \downarrow, \text { PTPRF } \downarrow, \\
\text { PTPRM } \downarrow, \text { SRC } \uparrow\end{array}$ \\
\hline $\begin{array}{l}\text { Arrhythmogenic right } \\
\text { ventricular cardiomyopathy }\end{array}$ & 6 & 0.0111 & $\begin{array}{l}\text { ACTN1 } 1, \text { CTNNA2 } \downarrow, \text { DSG } 2 \uparrow, \text { GJA } 1 \downarrow \text {, } \\
\text { ITGA3 } \uparrow, \text { ITGA6 } \uparrow\end{array}$ \\
\hline $\begin{array}{l}\text { Protein processing in } \\
\text { endoplasmic reticulum }\end{array}$ & 8 & 0.018 & $\begin{array}{l}\mathrm{BAX} \uparrow, \mathrm{DNAJA} 1 \uparrow, \mathrm{ERLEC} 1 \uparrow, \mathrm{ERP} 29 \downarrow, \mathrm{SEC} 23 \mathrm{~B} \uparrow, \\
\mathrm{SEC} 24 \mathrm{~B} \uparrow, \mathrm{UBQLN} 1 \uparrow, \mathrm{UGGT} 1 \downarrow\end{array}$ \\
\hline Focal adhesion & 9 & 0.018 & $\begin{array}{l}\text { ACTN1 } 1 \uparrow, \text { COL5A1 } \downarrow, \text { COL6A } 1 \downarrow, \text { COL6A3 } 3, \text { FN1 } 1, \\
\text { ITGA3 } \uparrow, \text { ITGA6 } \uparrow, \text { LAMC } 1 \downarrow, \text { SRC } \uparrow\end{array}$ \\
\hline Aminoacyl-tRNA biosynthesis & 4 & 0.0499 & AARS $\downarrow$, IARS $\downarrow$, MARS $\downarrow$, WARS $2 \downarrow$ \\
\hline
\end{tabular}

ECM-RECEPTOR INTERACTION
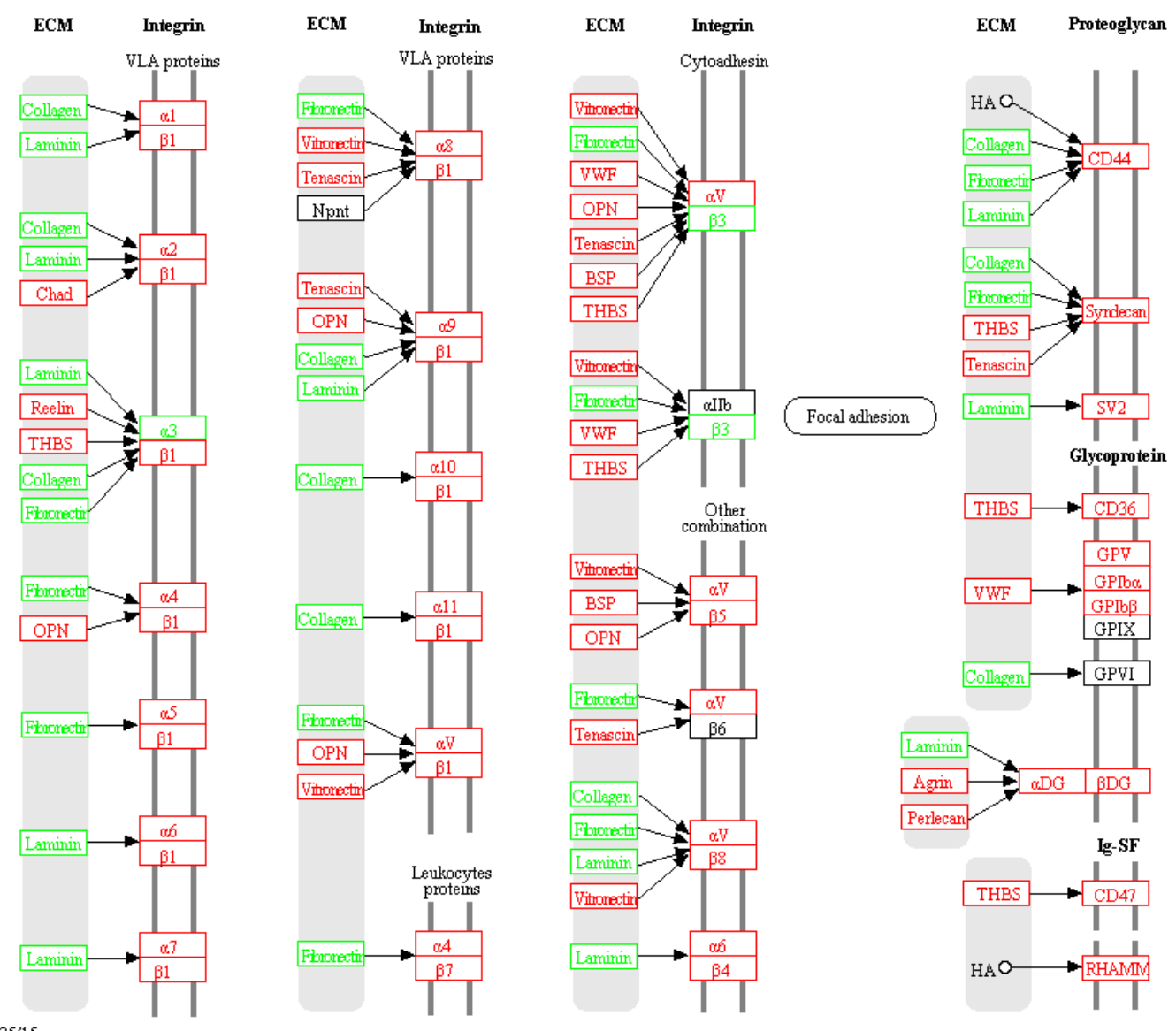

$0451211 / 25 / 15$
(c) Kanehisa Laboratories

Figure 5. DEPs in the ECM-receptor interaction pathway. Green block: DEPs; red block: genes in transcriptome of the PPCs.

\subsection{Expressed Stem Cell Surface Markers}

In addition to key stem cell membranous surface markers, CD9, CD90 and CD105, reported to be expressed in ASCs $[2,8,18]$, we detected in PPCs, new stem cell markers, CD73, CD90 and CD105 (known as classical markers for mesenchymal stem cells), and CD29, CD44 and CD166 (known as 
markers for adult stem cells) [19] (Table 2). Immunofluorescent staining further verified the expression of those stem cell surface markers (Figure 6).

Table 2. Expression of stem cell surface markers.

\begin{tabular}{ccc}
\hline Gene/Protein & Protein IDs & Average LFQ (Label-Free Quantitation) Intensity \\
\hline CD9 (MRP1) & P30932 & $3.24 \times 10^{8}$ \\
CD29 (ITGB1) & P53712 & $3.36 \times 10^{9}$ \\
CD44 (HCAM) & L8ITJ7 & $1.45 \times 10^{8}$ \\
CD73 (NT5E) & Q05927 & $6.20 \times 10^{8}$ \\
CD90 (THY1) & L8IGG9 & $9.42 \times 10^{8}$ \\
CD105 (ENG) & E1B7I8 & $5.164 \times 10^{7}$ \\
CD166 (ALCAM) & F1MHN8 & $4.75 \times 10^{8}$ \\
\hline
\end{tabular}

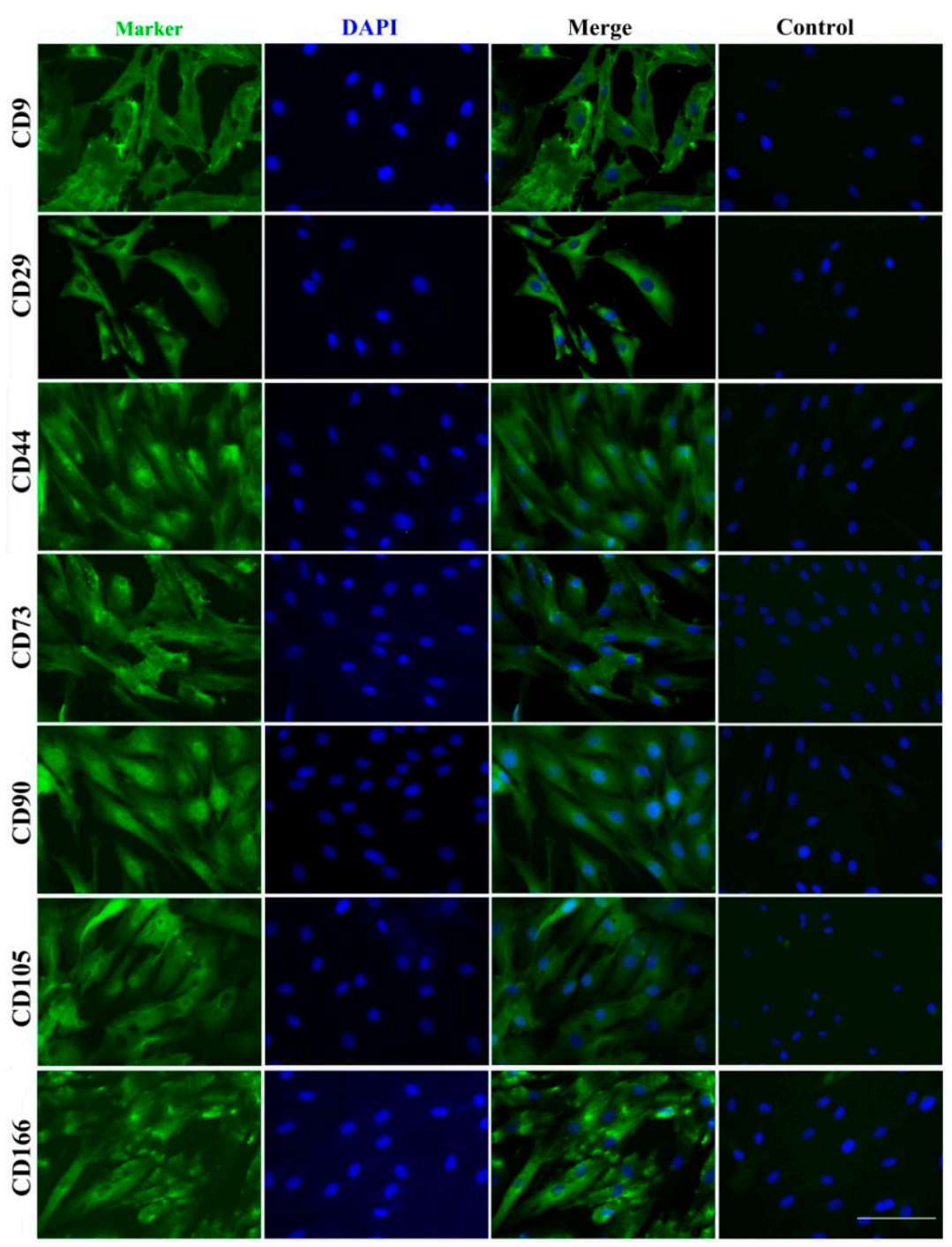

Figure 6. Immunofluorescent staining of surface stem cell markers. CD9, CD29, CD44, CD73, CD90, CD105 and CD166 were detected with their antibodies, and nuclei were counterstained with DAPI. Bar $=100 \mu \mathrm{m}$.

\subsection{Validated DEPS}

To validate expression levels of our detected DEPs, five proteins (Galectin1, CD9, ITGA3, RXFP2, and SPARC) were confirmed using Western blotting (Figure 7). CD9 and Galectin1 were reported to be expressed in the ASCs previously [13], ITGA3 and SPARC are critical node-proteins from the network 
(Figure 4), and RXFP2 could be used as the special marker for ASCs [20]. Expressions of Galectin1, CD9 and ITGA3 were found to be up-regulated in the PPCs, while SPARC was down-regulated, and RXFP2 was undetectable in the FPCs (Figure 7A). All five proteins (PPCs vs. FPCs) were highly significantly differentially expressed ( $p<0.01$; Figure 7B). Expression of CD9, ITGA3, RXFP2 and SPARC was consistent with those of LC-MS/MS results. Galectin-1 was found to be overexpressed (2 fold) in the PPCs vs. FPC, but did not reach a significant level $(p=0.054)$.
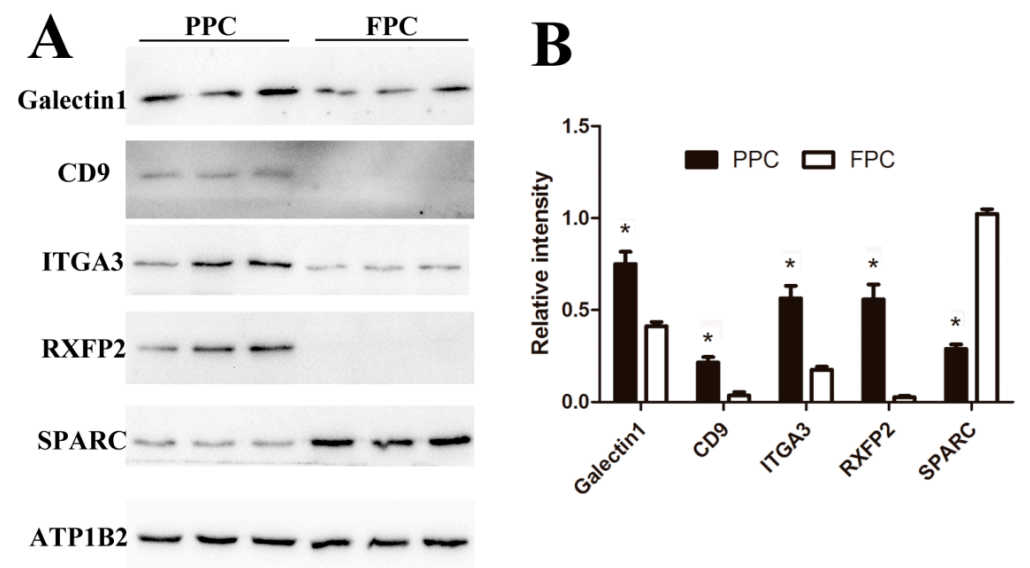

Figure 7. Verification of the DEPs via Western-blot analysis. (A) Immunoblot results of five DEPs and internal reference protein (ATP1B2). (B) Histogram of immunoblot analyzed using Image J (Version1.8.0, Bethesda, MD, USA) and normalized by ATP1B2. Values are mean $\pm \mathrm{SD},{ }^{*} p<0.05$.

\section{Discussion}

Pedicle periosteum cells (PPCs) include "stem cells" that support each annual round of full antler regeneration [2]. This study is the first analysis of plasma membrane proteins of PPCs using label-free LC-MS/MS. A total of 241 significant DEPs were detected in the PPCs vs. FPCs: 92 up-regulated and 149 down-regulated. Among these DEPs, 226 GO terms were identified, comprising six clusters of GO terms involving responses to external stimulus, signal transduction, membrane transport, protein modification, and regulation of tissue regeneration. Furthermore, numerous classical stem cell surface markers were detected, confirming PPCs belong to the stem cell family.

Plasma membrane proteins in cells constitute the sensitive interface between the external and internal environments, and readily react to internal and external stimuli and play central roles in various cellular processes including signal transduction, cell adhesion, and transport of molecules [10]. The fact that plasma membrane proteins accounted for $40.9 \%$ of the total proteins in the present study demonstrated that the enrichment process was successful. Although it is impossible to thoroughly purify plasma membrane proteins from organelle and cytoplasmic proteins [21], some non-membrane proteins may be structurally and/or functionally associated with the plasma membrane [22]. In living cells, while many proteins are permanently bound to the lipid bilayer, some proteins, so called "amphitropic proteins", are temporarily attached either to membrane proteins or to the lipid bilayer [23]. These proteins are recruited to cellular membranes under certain physiological conditions, such as cell signaling and membrane trafficking [24]. In this study, some non-membrane proteins were also isolated together with membrane proteins, indicating that these proteins are closely associated with membrane proteins. SPARC, TIMP2 and FGF7 can bind to membranes temporarily, and we believe that those "amphitropic proteins" are also involved in the control of antler regeneration.

Due to the nature of our study, i.e. purification of plasma membrane proteins, only six KEGG pathways were found to be significantly enriched from our DEPs, in particular, those of ECM-receptor interaction signaling pathways, which serve important roles in controlling cellular activities such as adhesion, migration, proliferation, differentiation and apoptosis [25]. In this study, ECM-receptor interaction was significantly enriched and seven related proteins were differentially highly expressed 
(Table 2), suggesting ECM-receptor interaction pathways could be involved in the regulation of antler regeneration.

Membranous proteins are usually involved at the starting point of signaling pathways, e.g. PI3K/AKT and VEGF signaling pathways, receptors in plasma membrane plays central roles in signal transmission $[26,27]$. In this study, several key regulatory proteins, such as TGFBR, VEGF, and ITGA/B were significantly up-regulated in the PPCs, indicating that the PI3K/AKT and VEGF signaling pathways are involved in rapid cell proliferation and angiogenesis during antler regeneration. VEGFR2 appears to be the most important receptor in controlling the migration and proliferation of endothelial cells and promoting their survival and vascular permeability [28]. The PI3K/AKT signal pathway regulates fundamental cellular functions such as cell-cycle progression, proliferation, differentiation, and survival [29].

TIMP2, down-regulated in the PPCs, is a potent inhibitor of the matrix metalloproteinases (MMP), a group of peptidases involve in ECM degradation. TIMP2 can form a complex with MMP2 to inhibit the activation of MMP2 [30]. Active MMP2 is required for the degradation of ECM, a key physiological process in embryonic development, angiogenesis, reproduction, and tissue remodeling [31,32]. ALCAM, also known as CD166, which is required to activate MMP2 [33], was also detected in the PPCs, suggesting MMP2 is active in the PPCs. Furthermore, ECM-receptor interaction was one of significantly enriched pathways in the present study (Table 2). This pathway controls cellular activities in a direct- or indirect-manner, such as proliferation, differentiation, adhesion, migration, and apoptosis [34,35]. Therefore, the expression of ALCAM and down-regulation of TIMP2 may play important roles in antler regeneration through the ECM-receptor interaction pathway.

The term "Antler stem cells (ASCs)" was put forward to define the cells that give rise to the first and subsequent antlers $[4,36]$ and cells from the antlerogenic periosteum (AP), pedicle periosteum (PP) and reserve mesenchyme (RM) $[8,18,37]$ have been isolated, cultured and partially characterized by several laboratories. CD9 was defined as a cell surface marker of ASCs in previous studies [2,38]. Rolf et al. [8] isolated Stro-1+ cells from the PP, and defined these cells as a type of mesenchymal stem cells (MSCs). CD73, CD90, and CD105 were known as classical markers of MSCs [19]; CD29, CD44 and CD166 were reported as markers for adult stem cells [39]. In this study, a series of stem cell surface markers (CD9, CD29, CD44, CD73, CD90, CD105, and CD166) were found in the membranous proteome of the PPCs, and validated using immunofluorescent staining (Figure 4); therefore, we further confirmed that the PPCs are a type of stem cell.

Male secondary sexual characters of deer antler development are under the control of endocrine factors, especially androgens [40]. Previous studies reported that development of antlers is fully dependent on the changes in androgen and IGF (Insulin-like Growth Factor) levels [2,41]. In vitro studies also show that IGF1 has direct dose-dependent mitogenic effects on the proliferation of antler stem cells (ASCs) [42], whereas, androgens fail to influence the mitogenesis of ASCs [43]. In this study, a cluster containing eight GO terms involving response to external stimuli were enriched, including response to hormones (25 proteins) (Figure 3). Verification of the function of these proteins will help us to reveal the regulatory mechanism of androgens on the initiation of antler formation.

Tissue/organ regeneration is a very complicated process. The liver is unique for its ability to regenerate. More than 100 genes are activated immediately after partial hepatectomy [44] and thousands of genes changed in the expression level within the first hour after partial hepatectomy [45]. EGF, FGF-1, TNF- $\alpha$, IL-6, and TGF- $\beta$ play important roles in liver regeneration, however, loss of function of any single gene rarely leads to complete blockage of liver regeneration [46]. Urodele amphibians have the unique ability to regenerate lost limbs. After amputation, cells proximal to the wound surface, including epidermis, dermis, muscle, and cartilage cells, can achieve a multipotential state through dedifferentiation and formed blastema [47]. In the axolotl, de-differentiated cells keep a memory of their tissue origin and re-differentiation back during limb regeneration [48]. Deer antlers are unique in that their regeneration is derived from a single tissue type, i.e. the PP [2]. Li et al. labeled a group of ASCs before antler growth in vivo and found labeled cell progeny in all types of tissues in 
antlers, including bone, cartilage, dermis and blood vessels [49]. In this study, 24 GO terms involved in the regulation of tissue regeneration were enriched from DEPs in the PPCs vs. FPCs; including wound healing, cell migration, and vasculature development, (Figure 3). We believe that these DEPs or specific regulatory pathways play central roles in ASC biology and antler regeneration.

\section{Materials and Methods}

\subsection{Tissue Sampling and Cell Culture}

The PP and FP were aseptically collected from 2-year-old male sika deer immediately after slaughtering. Location of the PP and FP are shown in Figure S2. Three biological replicates for both PP and FP were designed, and the corresponding cell lines were created according to the previously reported methodology [14]. All of the above cell types were cultured in Dulbecco modified Eagle medium (DMEM) (Gibco; Grand Island, NY, USA), supplemented with 10\% fetal bovine serum (FBS, Gibco), $100 \mathrm{mg} / \mathrm{mL}$ of streptomycin, and 100 units $/ \mathrm{mL}$ of penicillin, and incubated in a humidified atmosphere with $5 \% \mathrm{CO}_{2}$ at $37^{\circ} \mathrm{C}$. Tissue collection from the slaughtered deer heads in this study was approved by the CAAS Animal Ethics Committee (CAAS2017046C, 22 March 2017).

\subsection{Plasma Membrane Protein Isolation}

Plasma membrane proteins of the PPCs and FPCs were isolated using Minute ${ }^{\mathrm{TM}}$ Plasma Membrane Protein Isolation Kit (Invent biotechnologies, Eden Prairie, MN, USA) following the manufacturer's procedure. Briefly, three 100-mm culture dishes of cells (about $3 \times 10^{6}$ ) for each sample were harvested using a sterile cell scraper, and washed twice with cold phosphate buffered saline (PBS). The cell pellet was resuspended with buffer A containing protease inhibitors, and subjected to 10 cycles of sonication ( $5 \mathrm{~s}$ on $/ 5 \mathrm{~s}$ off). Cell suspensions were transferred to filter cartridges and centrifuged at $16,000 \mathrm{~g}$ for $30 \mathrm{~s}$. The cell pellet was resuspended again and nucleus $(700 \times g, 1 \mathrm{~min})$, cytosol fraction and membrane protein $(16,000 \times g, 30 \mathrm{~min})$ were successively separated through gradient centrifugation. Total membrane proteins were resuspended with buffer $\mathrm{B}$, organelle membranes $(7800 \times \mathrm{g}, 20 \mathrm{~min})$ and plasma membranes $(16,000 \times g, 20 \mathrm{~min})$ were separated once more by gradient centrifugation. The pellet of plasma membrane proteins was dissolved in $200 \mu \mathrm{L}$ Protein Extraction Buffer.

\subsection{Protein Identification and Quantification Using LC-MS/MS}

LC-MS/MS analysis was carried out as described elsewhere [50]. Briefly, the proteins (100 $\mu \mathrm{g}$ of each sample) were digested with $3 \mu \mathrm{g}$ trypsin (Promega, Fitchburg, MA, USA) in $40 \mu \mathrm{L} 25 \mathrm{~mm}$ $\mathrm{NH}_{4} \mathrm{HCO}_{3}$ at $37^{\circ} \mathrm{C}$ overnight. The concentration of peptides was estimated by MicroBCA assay (Thermo, Rockford, IL, USA). The peptides of each sample were separated on the UltiMate 3000 RSLCnano high-performance liquid chromatography (HPLC) system using a C18 BEH column and C18 Acclaim PepMap RSLC column (Thermo). Peptides were subsequently separated in a linear gradient acetonitrile (from $4 \%$ to $35 \%$ with $0.1 \%$ formic acid) over $140 \mathrm{~min}$ and $35-45 \%$ over $10 \mathrm{~min}$. At $160 \mathrm{~min}$, the gradient increased to $95 \%$ for $10 \mathrm{~min}$. Peptides eluting from the column were analyzed by MS/MS using a Thermo Scientific Q Exactive Orbitrap mass spectrometer (Thermo). MS scans were set at a resolution of 70,000 and 17,500 for the data-dependent MS/MS scans. The MS scan range was from 300 to $1800 \mathrm{~m} / z$. The peptide signals were then mapped across multiple LC-MS measurements using their coordinates on the mass-to-charge and retention-time dimensions. The total ion current of the peptide signal was then integrated and used as a quantitative measurement of the original peptide concentration. The MS data were analyzed using MaxQuant software version1.5.3.17 (Max Planck Institute of Biochemistryin, Martinsried, Germany) [51], and the parameters were set up following Table 3. Statistical analysis was performed with the $t$-test using SAS (Statistical Analysis System) version 9.0. Fold change $>1.5$ and $p<0.05$ were defined as significantly different in this study. 
Table 3. Parameters setting in MaxQuant comparative analysis.

\begin{tabular}{cc}
\hline Item & Value \\
Enzyme & Trypsin \\
Max Missed Cleavages & 2 \\
Main search & $6 \mathrm{ppm}$ \\
First search & $20 \mathrm{ppm}$ \\
Mass spectrometry (MS/MS) Tolerance & $20 \mathrm{ppm}$ \\
Fixed modifications & Carbamidomethyl (C) \\
Variable modifications & Oxidation (M), Acetyl (Protein N-term) \\
Database & uniprot-Pecora_94642_20170405 \\
Database pattern & Reverse \\
Peptide FDR (False Discovery Rate) & $\leq 0.01$ \\
Protein FDR & $\leq 0.01$ \\
Time window (match between runs) & 2 min \\
Protein Quantification & Razor and unique peptides were used for \\
LFQ & protein quantification. \\
LFQ min. ratio count & True \\
& 1 \\
\hline
\end{tabular}

\subsection{Bioinformatics Analysis of DEPs}

The GO annotation and enrichment of DEPs was analyzed based on the mainstream database David 6.7 (http:/ / david.abcc.ncifcrf.gov/). The PANTHER (protein annotation through evolutionary relationship) classification system (http:/ / www.pantherdb.org/) was used to analyze the molecular characterization of differential proteins. GO results were further clustered using Enrichment Map plugin [16] in Cytoscape 3.1.1 with an overlap coefficient cutoff of 0.5 to generate a network map. The protein-protein interaction of differential proteins was conducted on the String (http://string-de.org/, version 10.0). The differential proteins were mapped to the KEGG database (https:/ / www.kegg.jp/ kegg/pathway.html) to enrich KEGG pathways.

\subsection{Western Blotting}

Plasma membrane proteins of the PPCs and FPCs were isolated as previously stated (2.2). Dissolved proteins were separated by $15 \%$ sodium dodecyl sulphate-polyacrylamide gel electrophoresis (SDS-PAGE) (20 $\mu \mathrm{g} /$ lane) and transferred to polyvinylidene fluoride (PVDF) membranes. Membranes were blocked with $5 \%(w / v)$ bovine serum albumin (BSA) and immunoblotted with suitably diluted primary antibody followed by secondary antibodies (goat anti-rabbit IgG or anti-mouse $\mathrm{IgG}$ ) conjugated with horse radish peroxidase. Bands were visualized using chemiluminescence detection reagents (Thermo) applied to autoradiograph films. The quantification of western blot bands was carried out using ImageJ software (version 2.1) normalized by internal reference. All primary antibodies used in this study are listed in Table 4.

Table 4. Antibodies used in this study.

\begin{tabular}{cccc}
\hline Terms & $\begin{array}{c}\text { Manufacturer and } \\
\text { Product Code }\end{array}$ & Isotype & Application \\
\hline CD9 & LSBio; LS-C46004 & Mouse, IgG2 & WB $^{1} 1: 500 ;$ \\
CD29 & Proteintech;12594-1 & Rabbit, IgG & IF 1:100 \\
CD44 & Proteintech; 15675-1 & Rabbit, IgG & IF 1:200 \\
CD73 & Santa; sc-25603 & Rabbit, IgG & IF 1:500 \\
CD90 & Bioss; bs-0778R & Rabbit, IgG & IF 1:100 \\
CD105 & Elabscience; ESH135 & Mouse, IgG1 & IF 1:500 \\
CD166 & Bioss; bs-1251R & Rabbit, IgG & IF 1:100 \\
\hline
\end{tabular}


Table 4. Cont.

\begin{tabular}{|c|c|c|c|}
\hline Terms & $\begin{array}{l}\text { Manufacturer and } \\
\text { Product Code }\end{array}$ & Isotype & Application \\
\hline Galectin-1 & Self-produced & Rabbit, serum & WB 1:100 \\
\hline SPARC & Proteintech; 15274-1 & Rabbit, IgG & WB 1:500 \\
\hline ITGA3 & Bioss; bs-6328R & Rabbit, IgG & WB 1:200 \\
\hline ATP1B2 & Bioss; bs-23414R & Rabbit, IgG & WB 1:500 \\
\hline RXFP2 & Self-produced & Rabbit, serum & WB 1:200 \\
\hline Rabbit IgG-Isotype control & Abcam, ab172730 & & IF 1:200 \\
\hline Mouse IgG-Isotype control & Abcam, ab37355 & & IF 1:200 \\
\hline $\begin{array}{l}\text { HRP-conjugated goat } \\
\text { anti-rabbit IgG }(\mathrm{H}+\mathrm{L})\end{array}$ & Beyotime, A0208 & & WB 1:2000 \\
\hline $\begin{array}{l}\text { HRP-conjugated goat } \\
\text { anti-mouse IgG }\end{array}$ & Beyotime, A0216 & & WB: 1:2000 \\
\hline $\begin{array}{l}\text { Goat anti-rabbit IgG H\&L } \\
\text { (Alexa Fluor 488) }\end{array}$ & Abcam, ab150077 & & IF $1: 1000$ \\
\hline $\begin{array}{l}\text { Goat Anti-mouse IgG H\&L } \\
\text { (Alexa Fluor 488) }\end{array}$ & Abcam, 150113 & & IF 1:1000 \\
\hline
\end{tabular}

${ }^{1}$ WB Western blot; ${ }^{2}$ IF Immunofluorescence.

\subsection{Immunofluorescent Staining}

Immunofluorescent staining was carried out as described elsewhere [52]. Briefly, cells were seeded on sterile glass cover slips in 24-well plates a day before. Cover slips with adhered cells were rinsed with PBS and fixed in $4 \%$ formaldehyde for $20 \mathrm{~min}$. Cells were washed with PBS three times, and blocked with 5\% normal goat serum in PBS for $30 \mathrm{~min}$. Cells were incubated with diluted primary antibody overnight at $4{ }^{\circ} \mathrm{C}$, and isotype-matched rabbit or mouse IgG served as the negative controls. Cells were rinsed three times in PBS and incubated with fluorescein-conjugated secondary antibody for 1 hour at room temperature (RT) in the dark. The nuclei of cells were counterstained with DAPI for $5 \mathrm{~min}$ at RT. Following washing, the cover slips were mounted on glass slides with anti-fade reagent and examined under a fluorescent microscope.

\section{Conclusions}

Overall, this is the first isolation and analysis of the plasma membrane and associated proteins of ASCs. In this study, we have identified a large number of membrane proteins specifically expressed in the PPCs and stem cell surface markers using the technique of label-free LC-MS/MS. Identified DEPs enriched a set of GO terms impacting various biological processes. Further studies are required to demonstrate the relevance of these proteins and GO terms in ASC biology and antler regeneration.

Supplementary Materials: Supplementary materials can be found at http:/ / www.mdpi.com/1422-0067/19/11/ $3477 /$ s1.

Author Contributions: Conceptualization, D.W. and C.L.; Data curation, D.W. and Q.Z.; Formal analysis, H.B.; Funding acquisition, C.L.; Methodology, H.B. and C.L.; Project administration, D.W. and Q.Z.; Resources, C.L.; Validation, D.W., H.B., and C.L.; Visualization, H.B. and C.L.; Writing-original draft, D.W.; Writing-review and editing, C.L.

Funding: This research was funded by The National Natural Science Fund of China, grant number 31500792", "The Strategic Priority Research Program of the Chinese Academy of Sciences, grant number XDA16010105" and "Central Public-interest Scientific Institution Basal Research Fund, grant number 1610342016021".

Acknowledgments: The authors like to thank Eric Lord for carefully reading through the manuscript.

Conflicts of Interest: The authors declare no conflict of interest. The funders had no role in the design of the study; in the collection, analyses, or interpretation of data; in the writing of the manuscript, or in the decision to publish the results. 


\section{References}

1. Stocum, D.L. Regenerative Biology \& Medicine. In Tissue Restoration through Regenerative Biology and Medicine; Elsevier Academic Press: Boston, MA, USA, 2006; Volume 176, pp. 1-20.

2. Li, C.; Yang, F.; Sheppard, A. Adult stem cells and mammalian epimorphic regeneration-insights from studying annual renewal of deer antlers. Curr. Stem Cell Res. Ther. 2009, 4, 237-251. [CrossRef] [PubMed]

3. Goss, R.J. Future directions in antler research. Anat. Rec. 1995, 241, 291-302. [CrossRef] [PubMed]

4. Li, C.; Suttie, J.M.; Clark, D.E. Morphological observation of antler regeneration in red deer (Cervus elaphus). J. Morphol. 2004, 262, 731-740. [CrossRef] [PubMed]

5. Li, C.; Suttie, J.M.; Clark, D.E. Histological examination of antler regeneration in red deer (Cervus elaphus). Anat. Rec. Part A Discov. Mol. Cell. Evol. Biol. 2005, 282, 163-174. [CrossRef] [PubMed]

6. Kierdorf, U.; Stoffels, E.; Stoffels, D.; Kierdorf, H.; Szuwart, T.; Clemen, G. Histological studies of bone formation during pedicle restoration and early antler regeneration in roe deer and fallow deer. Anat. Rec. Part A Discov. Mol. Cell. Evol. Biol. 2003, 273, 741-751. [CrossRef] [PubMed]

7. Li, C.; Mackintosh, C.G.; Martin, S.K.; Clark, D.E. Identification of key tissue type for antler regeneration through pedicle periosteum deletion. Cell Tissue Res. 2007, 328, 65-75. [CrossRef] [PubMed]

8. Rolf, H.J.; Kierdorf, U.; Kierdorf, H.; Schulz, J.; Seymour, N.; Schliephake, H.; Napp, J.; Niebert, S.; Wolfel, H.; Wiese, K.G. Localization and characterization of STRO-1 cells in the deer pedicle and regenerating antler. PLoS ONE 2008, 3, e2064. [CrossRef] [PubMed]

9. Wallin, E.; Heijne, G.V.; Wallin, E.; von Heijne, G. Genome-wide analysis of integral membrane proteins from eubacterial, archaean, and eukaryotic organisms. Protein Sci. 2008, 7, 1029-1038. [CrossRef] [PubMed]

10. Josic, D.; Clifton, J.G. Mammalian plasma membrane proteomics. Proteomics 2010, 7, 20. [CrossRef] [PubMed]

11. Zhang, R.R.; Liu, H.M.; Shao, Y.C.; Zhou, P.Y.; Ying, S.U.; Wang, L.; Xing, X.M. Comparative Proteomic Analysis in Different Growth Stages of Sika Deer Velvet Antler. Chin. J. Anim. Vet. Sci. 2016, 47, 493-501.

12. Dong, Z.; Ba, H.; Zhang, W.; Coates, D.; Li, C. iTRAQ-Based Quantitative Proteomic Analysis of the Potentiated and Dormant Antler Stem Cells. Int. J. Mol. Sci. 2016, 17, 1778. [CrossRef] [PubMed]

13. Li, C.; Harper, A.; Puddick, J.; Wang, W.; McMahon, C. Proteomes and signalling pathways of antler stem cells. PLoS ONE 2012, 7, e30026. [CrossRef] [PubMed]

14. Li, C.; Suttie, J.M. Tissue collection methods for antler research. Eur. J. Morphol. 2003, 41, 23-30. [CrossRef] [PubMed]

15. Shannon, P.; Markiel, A.; Ozier, O.; Baliga, N.S.; Wang, J.T.; Ramage, D.; Amin, N.; Schwikowski, B.; Ideker, T. Cytoscape: A Software Environment for Integrated Models of Biomolecular Interaction Networks. Genome Res. 2003, 13, 2498-2504. [CrossRef] [PubMed]

16. Merico, D.; Isserlin, R.; Stueker, O.; Emili, A.; Bader, G.D. Enrichment Map: A Network-Based Method for Gene-Set Enrichment Visualization and Interpretation. PLoS ONE 2010, 5, e13984. [CrossRef] [PubMed]

17. Boginski, V.; Commander, C.W. Identifying Critical Nodes in Protein-Protein Interaction Networks. Clust. Chall. Biol. Netw. 2009, 153-167. [CrossRef]

18. Seo, M.S.; Park, S.B.; Choi, S.W.; Kim, J.J.; Kim, H.S.; Kang, K.S. Isolation and characterization of antler-derived multipotent stem cells. Cell Transplant. 2014, 23, 831-843. [CrossRef] [PubMed]

19. Keating, A. Mesenchymal Stromal Cells: New Directions. Cell Stem Cell 2012, 10, 709-716. [CrossRef] [PubMed]

20. Wiedemar, N.; Drögemüller, C. A 1.8-kb insertion in the $3^{\prime}$-UTR of RXFP2 is associated with polledness in sheep. Anim. Genet. 2015, 46, 457-461. [CrossRef] [PubMed]

21. Correani, V.; Francesco, L.D.; Mignogna, G.; Fabrizi, C.; Leone, S.; Giorgi, A.; Passeri, A.; Casata, R.; Fumagalli, L.; Maras, B. Plasma Membrane Protein Profiling in Beta-Amyloid-Treated Microglia Cell Line. Proteomics 2017, 17, 1600439. [CrossRef] [PubMed]

22. Goñi, F.M. Non-permanent proteins in membranes: When proteins come as visitors (Review). Mol. Membr. Biol. 2002, 19, 237-245. [CrossRef] [PubMed]

23. Burn, P. Amphitropic proteins: A new class of membrane proteins. Trends Biochem. Sci. 1988, 13, 79-83. [CrossRef]

24. Cho, W.; Stahelin, R.V. Membrane-Protein Interactions in Cell Signaling and Membrane Trafficking. Annu. Rev. Biophys. Biomol. Struct. 2005, 34, 119-151. [CrossRef] [PubMed] 
25. Milner, R.; Campbell, I.L. The integrin family of cell adhesion molecules has multiple functions within the CNS. J. Neurosci. Res. 2002, 69, 286-291. [CrossRef] [PubMed]

26. Stuttfeld, E.; Ballmerhofer, K. Structure and function of VEGF receptors. Iubmb Life 2010, 61, 915-922. [CrossRef] [PubMed]

27. Gao, X.; Lowry, P.R.; Zhou, X.; Depry, C.; Wei, Z.; Wong, G.W.; Zhang, J. PI3K/Akt signaling requires spatial compartmentalization in plasma membrane microdomains. Proc. Natl. Acad. Sci. USA 2011, 108, 14509-14514. [CrossRef] [PubMed]

28. Hoeben, A.; Landuyt, B.; Highley, M.S.; Wildiers, H.; Oosterom, A.T.V.; Bruijn, E.A.D. Vascular Endothelial Growth Factor and Angiogenesis. Pharmacol. Rev. 2004, 56, 549. [CrossRef] [PubMed]

29. Engelman, J.A.; Ji, L.; Cantley, L.C. The evolution of phosphatidylinositol 3-kinases as regulators of growth and metabolism. Nat. Rev. Genet. 2006, 7, 606-619. [CrossRef] [PubMed]

30. Morgunova, E.; Tuuttila, A.; Bergmann, U.; Tryggvason, K. Structural insight into the complex formation of latent matrix metalloproteinase 2 with tissue inhibitor of metalloproteinase 2. Proc. Natl. Acad. Sci. USA 2002, 99, 7414-7419. [CrossRef] [PubMed]

31. Mccawley, L.J.; Matrisian, L.M. Matrix metalloproteinases: Multifunctional contributors to tumor progression. Mol. Med. Today 2000, 6, 149-156. [CrossRef]

32. Rojiani, M.V.; Alidina, J.; Esposito, N.; Rojiani, A.M. Expression of MMP-2 correlates with increased angiogenesis in CNS metastasis of lung carcinoma. Int. J. Clin. Exp. Pathol. 2010, 3, 775-781. [PubMed]

33. Lunter, P.C.; van Kilsdonk, J.W.J.; van Beek, H.; Cornelissen, I.M.H.A.; Bergers, M.; Willems, P.H.G.M.; van Muijen, G.N.P.; Swart, G.W.M. Activated Leukocyte Cell Adhesion Molecule (ALCAM/CD166/MEMD), a Novel Actor in Invasive Growth, Controls Matrix Metalloproteinase Activity. Cancer Res. 2005, 65, 8801-8808. [CrossRef] [PubMed]

34. Goldbrunner, R.H.; Bernstein, J.J.; Tonn, J.C. ECM-mediated glioma cell invasion. Microsc. Res. Tech. 1998, 43, 250-257. [CrossRef]

35. Mecham, R.P. The Extracellular Matrix: An Overview; Springer: Heidelberg, Germany, 2010; pp. 1-17.

36. Price, J.; Faucheux, C.; Allen, S. Deer antlers as a model of Mammalian regeneration. Curr. Top. Dev. Biol. 2005, 67, 1-48. [CrossRef] [PubMed]

37. Li, C. Deer antler regeneration: A stem cell-based epimorphic process. Birth Defects Res. Part C Embryo Today Rev. 2012, 96, 51-62. [CrossRef] [PubMed]

38. Dabrowska, N.; Kielbowicz, Z.; Nowacki, W.; Bajzert, J.; Reichert, P.; Biezynski, J.; Zebrowski, J.; Haczkiewicz, K.; Cegielski, M. Antlerogenic stem cells: Molecular features and potential in rabbit bone regeneration. Connect. Tissue Res. 2015, 57, 1-37. [CrossRef] [PubMed]

39. Pazhanisamy, S. Adult Stem Cell and Embryonic Stem Cell Markers. Mater. Methods 2013, 3, 200. [CrossRef]

40. Suttie, J.M.; Lincoln, G.A.; Kay, R.N. Endocrine control of antler growth in red deer stags. J. Reprod. Fertil. 1984, 71, 7-15. [CrossRef] [PubMed]

41. Elliott, J.L.; Oldham, J.M.; Ambler, G.R.; Bass, J.J.; Spencer, G.S.; Hodgkinson, S.C.; Breier, B.H.; Gluckman, P.D.; Suttie, J.M. Presence of insulin-like growth factor-I receptors and absence of growth hormone receptors in the antler tip. Endocrinology 1992, 130, 2513-2520. [CrossRef] [PubMed]

42. Sadighi, M.; Haines, S.R.; Skottner, A.; Harris, A.J.; Suttie, J.M. Effects of insulin-like growth factor-I (IGF-I) and IGF-II on the growth of antler cells in vitro. J. Endocrinol. 1994, 143, 461-469. [CrossRef] [PubMed]

43. Li, C.; Wang, W.; Manley, T.; Suttie, J.M. No direct mitogenic effect of sex hormones on antlerogenic cells detected in vitro. Gen. Comp. Endocrinol. 2001, 124, 75-81. [CrossRef] [PubMed]

44. Taub, R. Liver regeneration 4: Transcriptional control of liver regeneration. FASEB J. 1996, 10, $413-427$. [CrossRef] [PubMed]

45. Arai, M.; Yokosuka, O.; Chiba, T.; Imazeki, F.; Kato, M.; Hashida, J.; Ueda, Y.; Sugano, S.; Hashimoto, K.; Saisho, H. Gene expression profiling reveals the mechanism and pathophysiology of mouse liver regeneration. J. Biol. Chem. 2003, 278, 29813-29818. [CrossRef] [PubMed]

46. Nelson, F.; Campbell, J.S.; Riehle, K.J. Liver regeneration. Hepatology 2006, 43, S45-S53.

47. Brockes, J.P. Amphibian limb regeneration: Rebuilding a complex structure. Science 1997, 276, 81-87. [CrossRef] [PubMed]

48. Kragl, M.; Knapp, D.; Nacu, E.; Khattak, S.; Maden, M.; Epperlein, H.H.; Tanaka, E.M. Cells keep a memory of their tissue origin during axolotl limb regeneration. Nature 2009, 460, 60-65. [CrossRef] [PubMed]

49. Li, C. Development of deer antler model for biomedical research. Recent Adv. Res. Updates 2003, 2, 19. 
50. Cholewa, B.; Pellitterihahn, M.C.; Scarlett, C.O.; Ahmad, N. Large-Scale Label-Free ComparativeProteomics Analysisof Polo-Like Kinase 1 Inhibition via the Small-Molecule InhibitorBI 6727 (Volasertib) in BRAFV600E Mutant Melanoma Cells. J. Proteome Res. 2014, 13, 5041-5050. [CrossRef] [PubMed]

51. Cox, J.; Mann, M. MaxQuant enables high peptide identification rates, individualized p.p.b.-range mass accuracies and proteome-wide protein quantification. Nat. Biotechnol. 2008, 26, 1367. [CrossRef] [PubMed]

52. Javed, A.; Zaidi, S.K.; Gutierrez, S.E.; Lengner, C.J.; Harrington, K.S.; Hovhannisyan, H.; Cho, B.C.; Pratap, J.; Pockwinse, S.M.; Montecino, M.; et al. In situ immunofluorescence analysis: Immunofluorescence microscopy. Methods Mol. Biol. 2004, 285, 23-28. [CrossRef] [PubMed]

(C) 2018 by the authors. Licensee MDPI, Basel, Switzerland. This article is an open access article distributed under the terms and conditions of the Creative Commons Attribution (CC BY) license (http:/ / creativecommons.org/licenses/by/4.0/). 